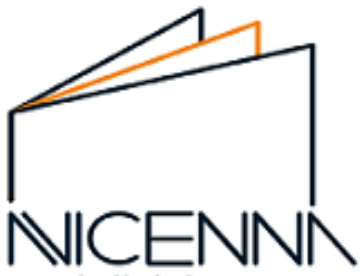

publishing co.

\title{
Asian Journal of Green Chemistry
}

journal homepage: http://ajgreenchem.avicenna.pub/

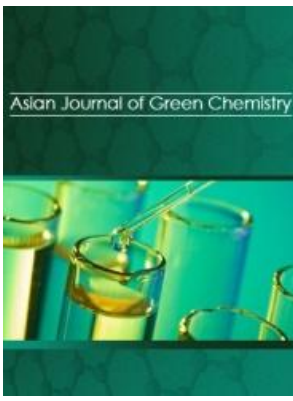

Original Research Article

\section{Production of biodiesel from jatropha curcas oil using solid heterogeneous acid catalyst}

\author{
Hadi Jabbari ${ }^{\mathrm{a}, *}$, Nader Noroozi Pesyan ${ }^{\mathrm{b}}$ \\ a Department of Management, Payam Noor University, Tehran, Iran \\ b Department of Organic chemistry, Faculty of chemistry, Urmia University, Urmia, 57159, Iran
}

\section{ARTICLE INFORMATION}

Received: 31 May 2017

Received in revised: 9 July 2017

Accepted: 10 July 2017

Available online: 11 July 2017

DOI: 10.22631/ajgc.2017.46511

\section{KEYWORDS}

\section{Biodiesel}

Transesterification

Solid base catalysts

Mg-Al hydrotalcites

Jatropha curcas oil

\begin{abstract}
Biodiesel produced by the transesterification of vegetable oils is a promising alternative fuel to diesel because of limited fossil fuel resources and environmental concerns. The use of heterogeneous catalysts greatly simplifies the technological process by facilitating the separation of the post-reaction mixture. The use of heterogeneous catalysts greatly simplifies the technological process by facilitating the separation of the post-reaction mixture. The purpose of the present work was to examine a heterogeneous catalyst, in particular, to produce methyl esters of jatropha curcas oil (JCO). In this study, the trans esterification of JCO with methanol was studied in a heterogeneous system, using Mg-Al hydrotalcites as solid base catalysts. The dependence of the conversion of JCO on the reactions variables such as the molar ratio of methanol/ oil, the amount of catalysts used, reaction temperatures and reaction times were performed. The conversion of $99 \%$ was achieved under the optimum reaction conditions.
\end{abstract}

\section{Graphical Abstract}

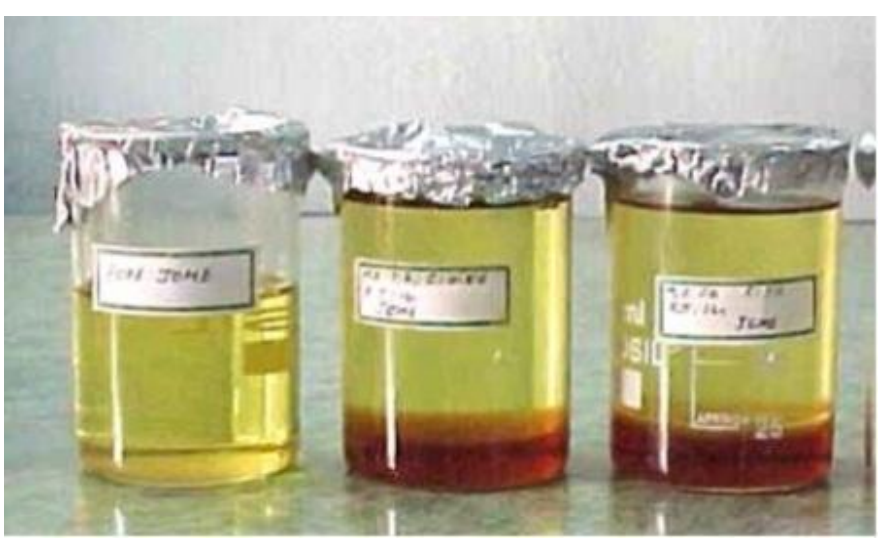

Corresponding author, email: hadijabbari@yahoo.com (H. Jabbari).

Tel.: +9844 33653791; Fax: +984434282484. 


\section{Introduction}

Biodiesel as an alternative fuel for diesel engines is becoming increasingly important due to diminishing petroleum reserves and the environmental consequences of exhaust gases from petroleum-fuelled engines. Biodiesel, which is made from renewable sources, consists of the simple alkyl esters of fatty acids. As a future prospective fuel, biodiesel has to compete economically with petroleum diesel fuels. One way of reducing the biodiesel production costs is to use the less expensive feedstock containing fatty acids such as inedible oils, animal fats, waste food oil and byproducts of the refining vegetables oils (Fig. 1) [1]. Biodiesel is a promising nontoxic and biodegradable renewable fuel comprised of mono-alkyl esters of long chain fatty acids, which are derived from vegetable oils or animal fats [2]. Biodiesel is oxygenated and essentially free of sulfur making it a cleaner burning fuel than petroleum diesel with reduced emissions of SOx, CO, unburnt hydrocarbons and particulate matter [3].

The acid-catalyzed process often uses sulfuric acid and hydrochloric acid as catalysts; however, the reaction time is very long (48-96 h), even at reflux of methanol, and a high molar ratio of methanol tooil is needed (30-150:1, by mole). Potassium hydroxide, sodium hydroxide, and their carbonates, as well as potassium and sodium alkoxides, such as $\mathrm{NaOCH}_{3}$, are usually used as base catalysts for this reaction. As the catalytic activity of a base is higher than that of an acid, and acid catalysts are more corrosive, the base-catalyzed process is preferred to the acid-catalyzed one, and is thus most often used commercially. Many different heterogeneous catalysts have been developed to catalyze the transesterification of vegetable oils to prepare fatty acid methyl esters. In recent years these materials have received considerable attention because they are used in a wide range of application such as adsorbent for liquid ions [4] and gas molecules [5]. They also find use as catalyst, precursors and other catalytic reactions [6]. Their most important applications are due to their permanent anion-exchange and adsorption capacity, the mobility of their interlayer anions and water molecules, their large surface areas and the stability and homogeneity of the materials formed by their thermal decomposition [7].

Decomposition of Mg-Al hydrotalcite yields a high surface area Mg-Al mixed oxide, which presumably exposes strong Lewis base sites (Fig. 2) [8-10]. The basic properties of these sites depend on the $\mathrm{Mg}-\mathrm{Al}$ ratio in the precursor hydrotalcite. Interestingly, the reconstruction of decomposed $\mathrm{Mg}-\mathrm{Al}$ hydrotalcite by rehydration at room temperature has been reported to enhance the catalytic activity $[11,12]$. During rehydration, the brucite-like layers are reformed and the charge-compensating carbonate anions are replaced by hydroxyl anions, thus forming Brønsted base sites. The decomposed-rehydrated $\mathrm{Mg}-\mathrm{Al}$ hydrotalcite with Brønsted base sites exhibits 
higher catalytic activity than the decomposed $\mathrm{Mg}-\mathrm{Al}$ hydrotalcite with Lewis base sites for the aldol condensation of benzaldehyde with acetone [13], aldol condensation of citral with ketones, selfaldolization of acetone, Michael addition reactions [14], and the transesterification of oleic acid methyl ester with glycerol.

It was reported that thermally activated $\mathrm{Mg}-\mathrm{Al}$ hydrotalcites with various $\mathrm{Mg}-\mathrm{Al}$ ratios were effective catalysts for transesterification of tributyrin with methanol, with increasing catalytic activity as the Mg content in the Mg-Al hydrotalcite increased [15].

Figure 1. Transesterification of vegetable oils

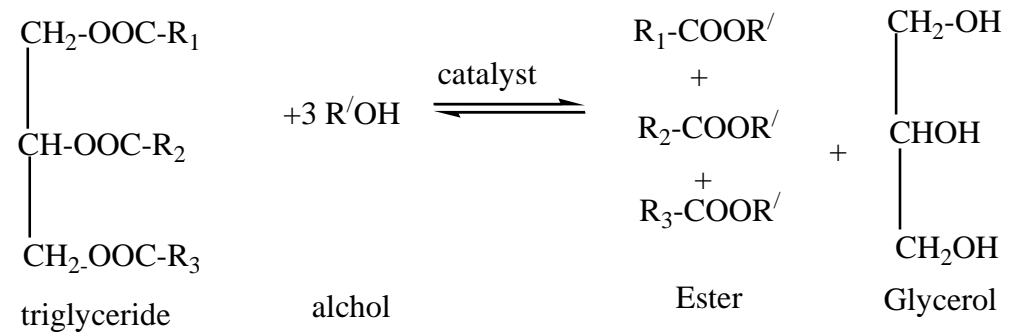

Figure 2. Hydrotalcite structure showing the brucite like layers and interlayer anions

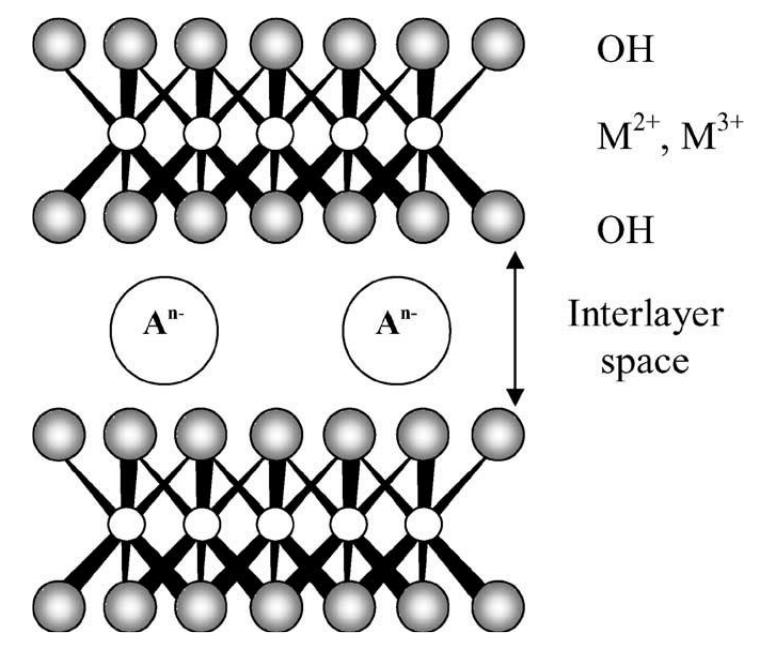

\section{Experimental}

Catalyst preparation

Catalyst preparation $\mathrm{Mg}$ containing hydrotalcites of the general formula [Mg(1_x $\left.) \operatorname{Alx}(\mathrm{OH})_{2}\right] \mathrm{x}+\left(\mathrm{CO}_{3}\right) \mathrm{x} / \mathrm{n}_{2}$ were synthesised as follows: $50 \mathrm{~cm}^{3}$ of distilled water was heated to $338 \mathrm{~K}$ unde rvigorous stirring. To this, $100 \mathrm{~cm}^{3}$ of an aqueous mixture of $\mathrm{x} \mathrm{mol} \mathrm{Mg}\left(\mathrm{NO}_{3}\right)_{2} \cdot 6 \mathrm{H}_{2} \mathrm{O}$ 
and y mol $\mathrm{Al}\left(\mathrm{NO}_{3}\right) 3.9 \mathrm{H}_{2} \mathrm{O}$ was added slowly over a period of $1 \mathrm{~h}$ along with $100 \mathrm{~cm}^{3}$ of an aqueous solution of $0.2 \mathrm{~mol}\left(\mathrm{NH}_{4}\right)_{2} \mathrm{CO}_{3}$. The $\mathrm{Mg}$ : $\mathrm{Al}$ ratio was varied such that $\mathrm{x}+\mathrm{y}=0.15 \mathrm{~mol}$ and $\mathrm{x}: \mathrm{y}=1: 1$, 2:1, $3: 1$ and $4: 1$. The $\mathrm{pH}$ of the mixture was continuously monitored by a Jenway $3030 \mathrm{pH}$ meter and held at $\mathrm{pH}=7.6-8$ by the drop wise addition of $\mathrm{NH}_{4} \mathrm{OH}$ (as $35 \%$ aqueous ammonia solution). The resulting mixture was held at $338 \mathrm{~K}$ while stirred vigorously for $3 \mathrm{~h}$ and then filtered and washed with distilled water until the filtrate was as near $\mathrm{pH}=7$ as possible. The precipitate was dried in an oven at 373-398 K for approximately $18 \mathrm{~h}$. All materials were calcined at $723 \mathrm{~K}$ for $3 \mathrm{~h}$ and cooled under a flowing stream of wet nitrogen (100 ml min-1, relative humidity 95\%) before catalyst testing.

General procedure for preparation of biodesel fuel from vegetable oils

In the transesterification of vegetable oils, a triglyceride reacts with an alcohol in the presence of a strong acid or base, producing a mixture of fatty acids alkyl esters and glycerol. The overall process is a sequence of three consecutive and reversible reactions, in which di and mono glycerides are formed as intermediates. The stoichiometric reaction requires $1 \mathrm{~mol}$ of a triglyceride and $3 \mathrm{~mol}$ of the alcohol. However, an excess of the alcohol is used to increase the yields of the alkyl esters and to allow its phase separation from the glycerol formed. Several aspects, including the type of catalyst (alkaline or acid), alcohol/vegetable oil molar ratio, temperature, purity of the reactants (mainly water content) and free fatty acid content have an influence on the course of the transesterification and will be discussed below, based on the type of catalyst used.

Transesterification reaction

JCO oil was obtained from a market. A $500 \mathrm{~cm}^{3}$ three-necked glass flask with a water-cooled condenser was charged with $50 \mathrm{~g}$ of JCO, methanol alcohol, and varied amounts of $\mathrm{Mg}-\mathrm{Al}$ hydrotalcite catalysts. The mixture was refluxed at the required temperature for $3 \mathrm{~h}$ under stirring at $500 \mathrm{rpm}$. After the reaction, the solid catalyst was separated by filtration. The liquid was put into a separating funnel and was kept at ambient temperature for $24 \mathrm{~h}$, after which 2 liquid phases appeared (Fig. 3). The upper layer was biodiesel and the lower layer was glycerol. The conversion of JCO was calculated from the quantity of total glycerol in the product.

\section{Results and discussion}

${ }^{1} \mathrm{H}$ NMR spectrum of methyl esters in general should present a signal in $\delta 3.7$ that is characteristic of oxymethylic hydrogen referent to methylic esters and shouldn't present signals between $\delta 4.0-4.3$ and $\delta 5.3$, referent to hydrogen of $\mathrm{CH}_{2}$ and $\mathrm{CH}$ glycerol group. When compared ${ }^{1} \mathrm{H}$ 
NMR spectrum of Jatropha oil with ${ }^{1} \mathrm{H}$ NMR spectrum of JOME sample, it can be verified that there is a singlet in $\delta 3.64$ that is characteristic of oxymethylic hydrogen, and this signal was attributed to esters (biodiesel), multiplet in $\delta 4.12-4.24$ and $\delta 5.30-5.34$ attributed to oxymethylic hydrogen that are characteristic of triglycerides from Jatropha oil (Fig. 4). From the NMR data it could be verified that Jatropha oil conversion into biodiesel was quite complete.

Figure 3. Jatropha biodiesel with glycerol samples

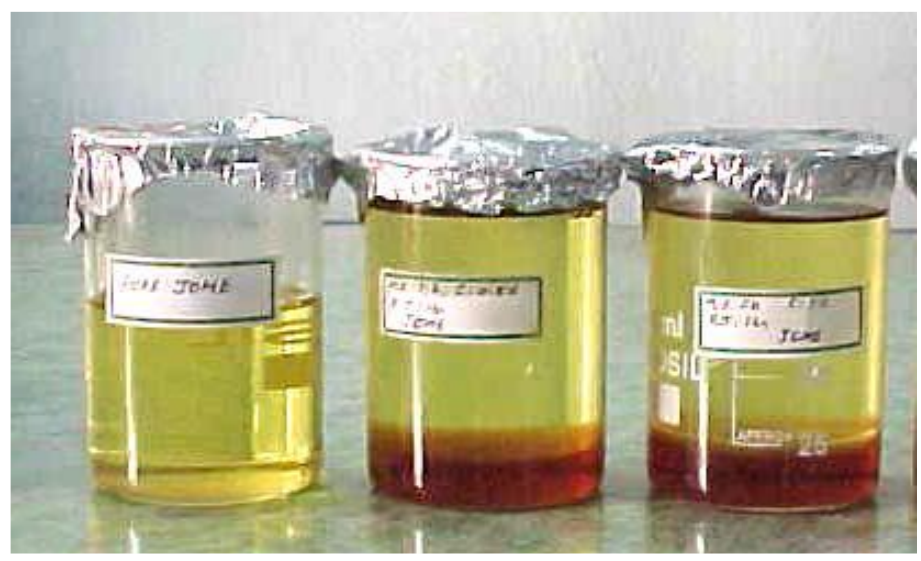

Effect of molar ratio of oil: Methanol and temperature on transesterification of JCO

The stoichiometric ratio for transesterification requires 3 moles of methanol for each mole of to $3 \mathrm{~mol}$ of fatty acid methyl ester and 1 mole of glycerol. Since the transesterification reaction is reversible reaction, excess methanol is required to drive the reaction towards product. As represented by Fig. 5, when methanol/oil molar ratio was increased, conversion was increased considerably. The maximum conversion was obtained when the methanol/oil ratio reach 15:1. There is evident that to elevate the conversion, an excessmethanol feed was effective only to a certain extent.

Effect of catalyst amount on the conversion

The influence of catalyst amount on the conversion of biodiesel was investigated. The catalyst amount was varied in the range of 1-5 wt.\%. As shown in Fig. 6, the conversion was increased with the increased of catalyst amount from 1 to $3 \mathrm{wt}$.\%. However, with further increased in the catalyst amount the conversion was slightly decreased. This was probably because the slurry (mixture of catalyst and reactants) become too viscous giving rise to a problem of mixing and demand of higher power consumption for adequate stirring. 


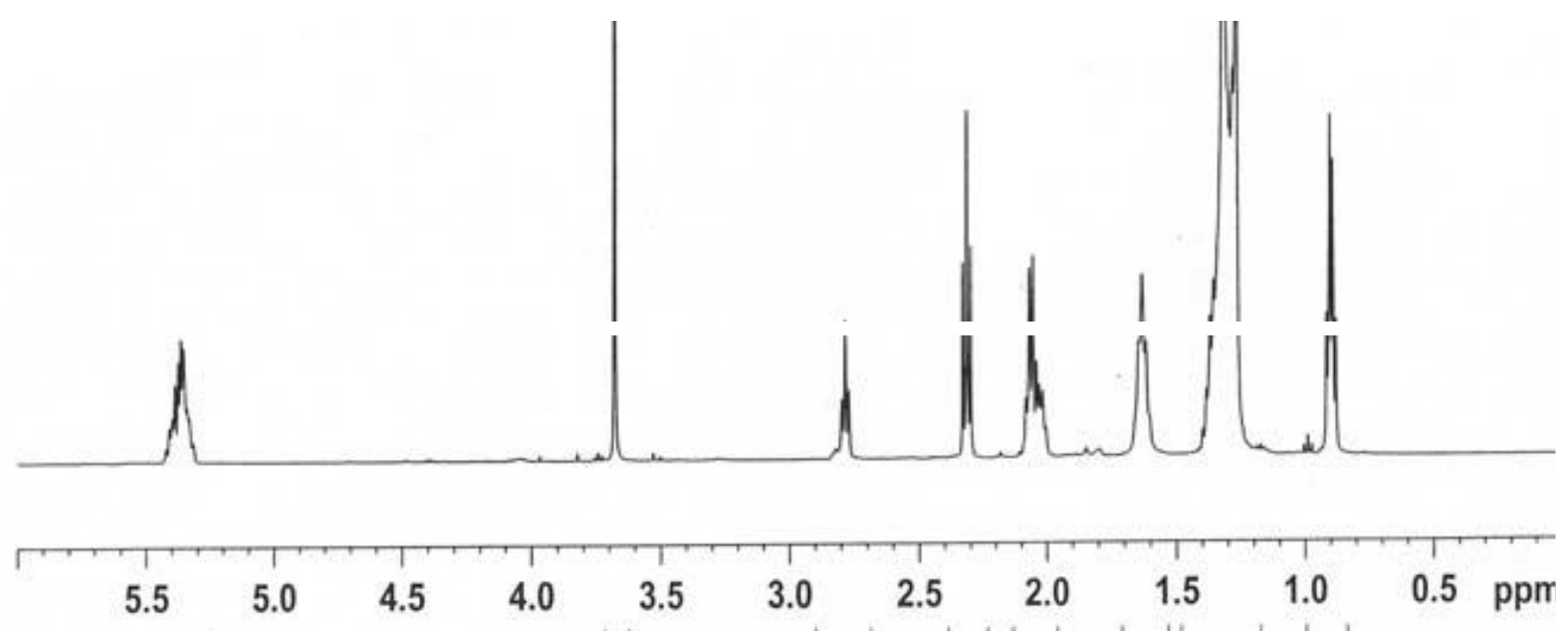

Figure 4. ${ }^{1} \mathrm{H}$ NMR spectrum of Jatropha oil methyl esters (JOMEs)

Figure 5. Influence of methanol/oil molar ratio on the conversion. Reaction condition: catalyst amount 3 wt.\%, reaction time 3 hours, reaction temperature $60^{\circ} \mathrm{C}$

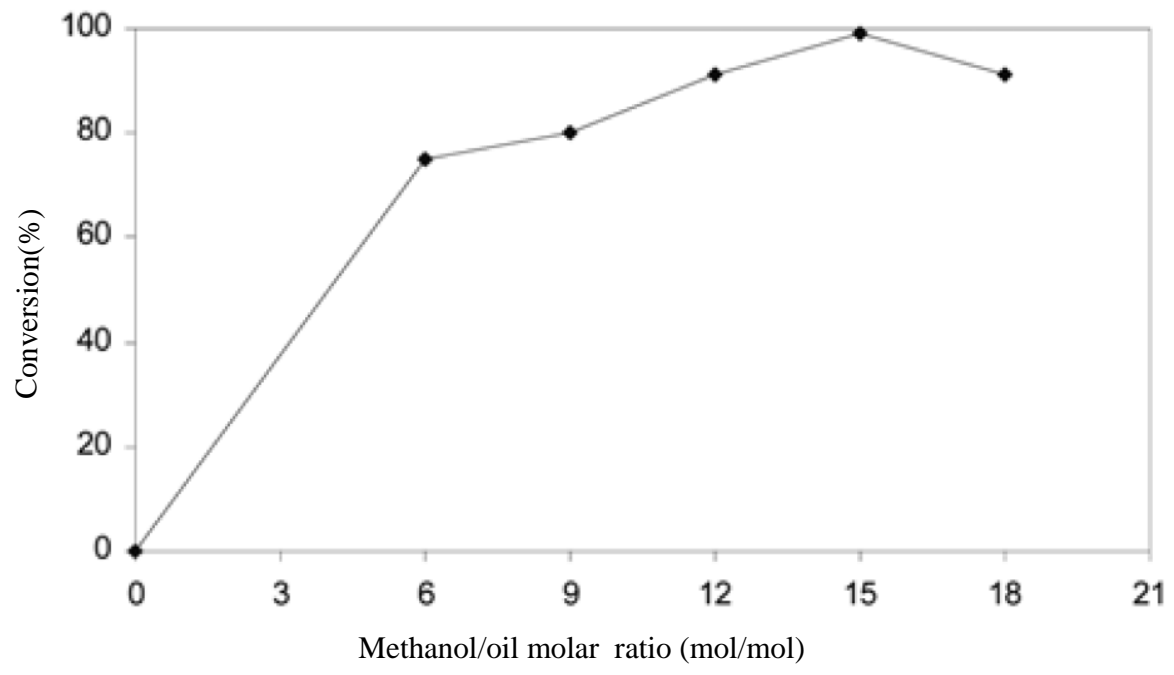

Figure 6. Influence of catalyst amount on the conversion. Reaction condition: methanol/oil molar ratio 15:1, reaction time 3 hours, reaction temperature $60{ }^{\circ} \mathrm{C}$

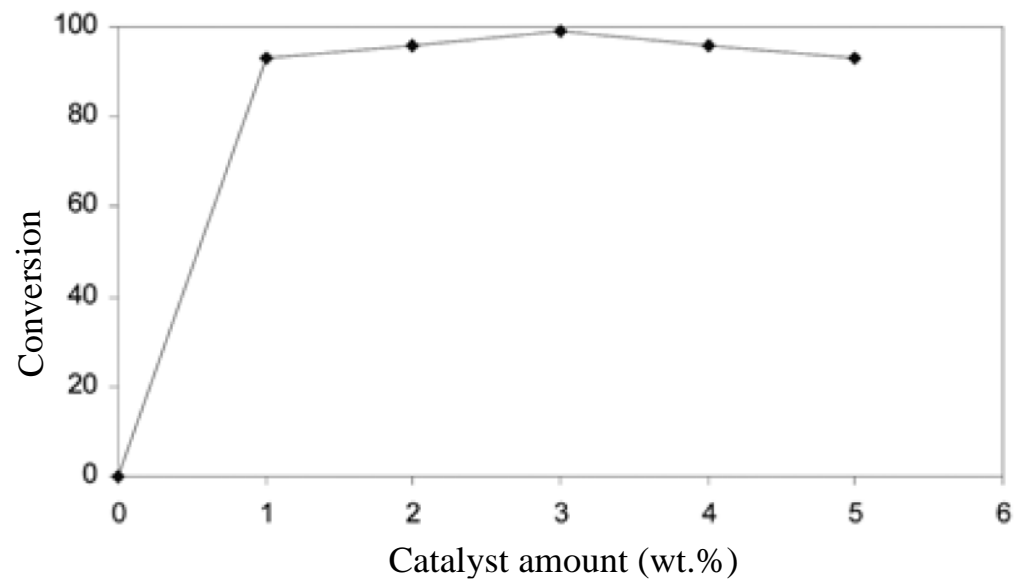




\section{Reaction time}

The influences of reaction time on JCO conversion are illustrated in Fig. 7. The reaction time was varied in the range 1-7 hours. As can be seen, the conversion was increased steadily in the first 3 hours and reached 99\% conversion. The conversion thereafter remained nearly constant after 3 hours of reaction time.

\section{Reaction Temperature}

Transesterification can occur at different temperatures depending on the types of catalyst and alcohol used. The influenced of reaction temperature on conversion of JCO to boidiesel was investigated with four different temperature. From the result shown in Fig. 8, the conversion increased as the reaction temperature increased and give the highest conversion of $99 \%$ at $60{ }^{\circ} \mathrm{C}$. However, when the temperature reaches to the boiling point of methanol, a lot of methanol's bubbles were formed hence inhibit the mass transfer on the phase interface thus lower the conversion.

Figure7. Influence of reaction time on conversion. Reaction condition: molar ratio methanol/oil 15:1, catalyst amount 3 wt.\%, reaction temperature $60^{\circ} \mathrm{C}$

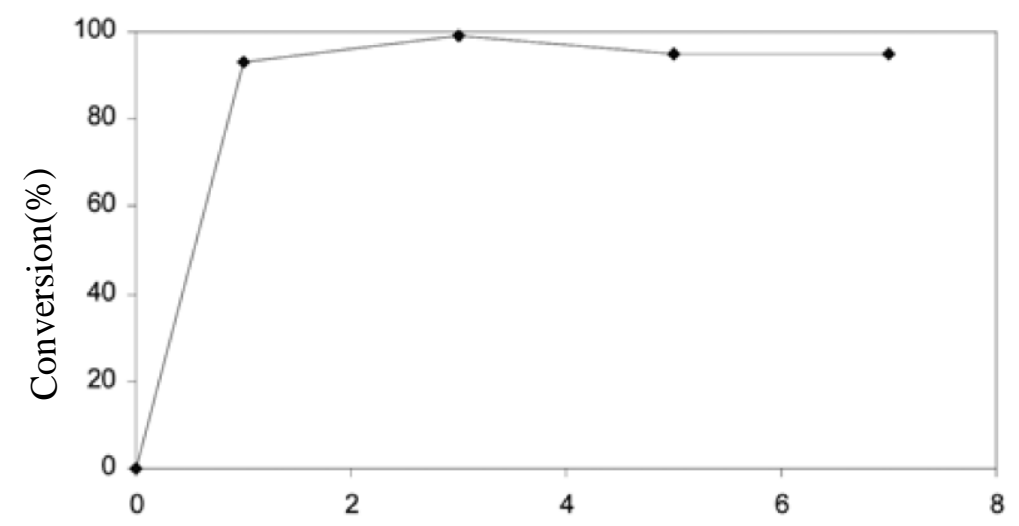

Figure 8. Influence of reaction temperature on conversion. Reaction condition: methanol/oil molar ratio $15: 1$, catalyst amount 3 wt $\%$, reaction time 3 hours

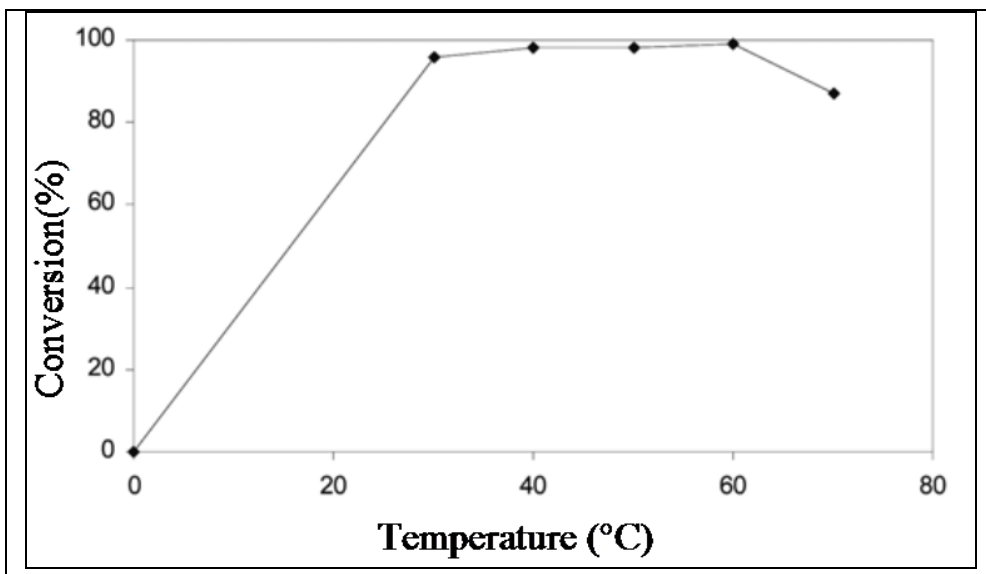




\section{Conclusion}

In this study the transesterification of JCO with methanol was studied in a heterogeneous system using Mg-Al hydrotalcites as solid base catalysts. Hydrotalcites were prepared by co-precipitation of magnesium and aluminum hydroxides from their nitrate solutions using an aqueous solution of sodium carbonate as the precipitating agent. The highest conversion 99\% reached when the reaction was carried out at $60{ }^{\circ} \mathrm{C}$ with molar ratio of methanol/oil (15:1), reaction time $3 \mathrm{~h}$ and catalyst amount $3 \mathrm{wt} \%$.

\section{Acknowledgments}

We are grateful to the research council of Urmia Payame Noor University for support of the present work.

\section{References}

[1]. MaF R., Hanna M.A. J. A Review Bioresour Technol, 1999, 70:1

[2]. Srivastava A., Prasad R. Renew Sustain Energy Rev., 2000, 4:111

[3] . Das J.D., Dash G.P., Parida K.M. Colloidal Interface Sci., 2002, 251:26

[4]. Yamamoto T., Kodama T., Hasegawa N., Tsuji M ., Tamaura T. Energy Conv., 1995, 36:637

[5]. Morato C., Alonso B., Coq F., Medina F., Cesteros Y., Sueiras J.E., Salagre P., Tichit D. Appl. Catal.

A: Gen., 2001, 32:167

[6]. Wang J.W., Kalinichev A.G., Kirkpatrick R.J., Hou X.Q. Chem. Mater., 2001, 13:145

[7]. Veloso C.O., Perez C.N., Souza B.M., Lima E.C., Dias A.G., Monteiro J.L.F., Henriques C.A. Micro. Meso. Mater., 2008, 5:107

[8]. Climent M., Corma J.A., Iborra S., Epping K., Velty A. J. Catal., 2004, 225:316

[9]. Tichit D., Guida A., Chiche Auroux B.H., Bartalini D., Garrone E. J. Catal., 1995, 151:50

[10]. Corma S., Abd Hamid S., Iborra S., Velty A. J. Catal., 2005, 5:340

[11]. Dicosimo J.I., Díez J.V. J. Catal., 1998, 178:499

[12]. Rao K.K., Gravelle M.J., Figueras F. J. Catal., 1998, 173:115

[13]. Abello S., Pérez-Ramírez J. Chem. Commun., 2005, 14:53

[14]. Choudary B.M., Kantam M.L., Aranganathan S., Santhia P.L,. Figueras F., J. Mol. Catal. A: Chem., 2000, 159:411

[15]. Cantrell D.G., Gillie L.J., Lee A.F., Wilson K. Appl. Catal. A: Gen., 2005, 287:183

How to cite this manuscript: Hadi Jabbari, Nader Noroozi Pesyan. Production of biodiesel from jatropha curcas oil using solid heterogeneous acid catalyst. Asian Journal of Green Chemistry, 2017, 1, 16-23. DOI: 10.22631/ajgc.2017.46511 